\title{
Recommendation letters and contacts: an implicit pull string to end with in academia
}

\author{
Khaled Moustafa* \\ *Editor of Arabic Science Archive (https://arabixiv.org) \\ Email: khaled.moustafa@arabixiv.org
}

\begin{abstract}
Objectivity and fairness are important characteristics of the scientific enterprise. However, the academic field is stuffed with many peculiarities that blemish it, such as the reliance on biased bibliometrics (journal impact factor, number of citations, ranking), cover letters, recommendation letters, age, etc. Recommendation letters and referees' opinions can be helpful in some cases but they are personal appreciations that differ from one individual to another and, hence, they should be used with caution or not at all as they can be easily influenced by different and changing factors to the detriment of objectivity and honesty.
\end{abstract}

Keywords: recommendation letter, letter of recommendation, reference contact, pull string, grant application, academic promotion, contact information, referees.

Recommendation or reference letters are oral or written testimonies expressed by supervisors or peers to commend applicants for admission in graduate programs, educational degrees, promotions, job positions or any other academic or professional purposes. The goal of recommendation letters or referees - as their names suggest- is to serve as references and to highlight accomplishments, experiences and skills of candidates. Ideally, they should emphasize in the applicant the intellectual curiosity, analytical and critical thinking, sense of responsibility, problem-solving skills, diligence, organization, motivation, integrity, leadership, autonomy, etc.

However, in most cases insightful stakeholders can infer such peculiarities and achievements of applicants from their curriculum vitae (CV) and from their publications list, making the letter of recommendation redundant or duplicate of the CV in some way or another. Depending on many personal and professional factors, such as the friendship level between referees and referred, and the common or opposite interests, etc., the content of recommendation letters could be easily inflated and dishonest [1] or in contrary implicitly 
slandering. When it is in-between (i.e., neutral and devoid of any glowing or bombastic expressions), the recommendation letters could be misinterpreted by stakeholders as negative or non-recommending statements that may result in the exclusion of potentially good applicants because of a subjective impression or a misinterpretation.

Due to subtle or blatant differences in judgment values between people, some statements or expressions could appear flattering at the first glance, but an evaluator may see them as an opposite or negative declaration, depending on how they are said, and by whom. For example, a phrase such as "showed improvement" is rated negative compared with "I give my highest recommendation" [2], though showing improvement is normally a good adaptive and skill-acquiring abilities, but paradoxically it is rated negatively as reported by Saudek [2].

A further drawback of the recommendation letter is that it may constitute a means of pulling strings in favor of some candidates, when it is written by prominent or 'star' supervisors compared with candidates who might not have such privileges. Conversely, when it is written by a young faculty member or a researcher who is not so familiar with recommendation codes, a reference letter, or referees opinions, may constitute some barriers to break down the aspirations of potentially interesting candidates. Actually, not because a person is a professor or researcher $\mathrm{s} /$ he is able to write good letters of recommendation that fit the expectations of managers or stakeholders. For example, the lack of impassion, unsubstantiated statements in a recommendation letter or hesitant tones in references' opinions could be badly interpreted by evaluators and, thus, compromising candidate applications. In other words, the likelihood of getting an academic or professional privilege may depend on who writes a recommendation letter and who reads it (interprets it) or who are the referees, and how they evaluate their trainees, but not necessarily on the skills and expertise that applicants can eventually bring to an organization.

Besides, without evidence opinions and personal judgments about someone else remain subjective and rarely accurate or absolute. Judgements and appreciations vary widely among people and could be influenced by many personal or professional factors such as the relationship level, the degree of friendship/cronyism, the conflict or contention, the competition, the previous mistakes or errors committed by trainees intentionally or unintentionally, etc., which can pop up to supervisors' or referees' minds at the moment of writing recommendation letters or referencing candidates to negatively influence their verdicts, consciously or unconsciously.

Human characters differ between people and the interpretation of recommendation letters also vary significantly [3]. As a result, two individuals (a supervisor and his or her trainee) might not get along with each other for different reasons but they can fully get along, each from his own side, with other people with different characters. The testimonial about a 
candidate can, therefore, be overestimated or in contrary underestimated as a function of the reciprocal appreciations between referees and trainees and their characters.

In general, stakeholders look for specific or strong expressions and statements in reference letters and referees' opinions. When they find them, they are more comfortable to make favorable decisions. However, a recommendation letter or reference's opinion could be glowing and flattering (for e.g., when it is well written by a renowned scholar or when it is laudatory), but later an applicant may appear below the expectations or under the oral or written testimonials expressed by referees or in the letter of recommendation. Conversely, an applicant could appear, in real situations, above the judgments and blessings of referees and recommendation letters.

Although the letters of recommendation could be part of the application process for some medical school and internal medicine residency [4] [ㄷ], they might appear as tempting ads or glowing notices that label many products in supermarkets or mass media but they do not necessarily reflect the real values of the advertised products. In fact, the recommendation letters share many of the deficiencies and biases of the cover letters [6] and they present many ethical, practical and plagiarism issues [7] [] [9] ]. In my view, recommendation letters and referees' opinions should be used with caution or not at all as they are mostly personal judgements that can be influenced by different and changing factors.

Most humans are smart enough to perform any kind of tasks or jobs when they are educated or trained to, whatever their background, age, skin color, countries, etc. Even animals (dogs, chimps, etc.) can perform tasks when they are trained to. Humans are more likely to do so. Associating the admission in graduate programs, promotions, job appointment, funding, etc., to recommendation letters and referees' opinions opens the door to biased practices and unfair competitions in favor of those who are well-endorsed compared with those who are not.

Finally, recommendations or references look like as accessories or a makeup operation that would not change or reflect the inherent value of a referred individual in different situations or circumstances. Education, learning and employments are professional fields whose the objectives are generally to build well-educated human societies and to advance the scientific knowledge as objectively as possible. All people should thus have equal opportunities for access to schools, universities, jobs, training, etc., without any distinction based on hyperbolizing expressions or endorsement letters or opinions made by this or that star or celebrity. Disqualifying people on the basis of reference letters or any subjective personal judgments is counterproductive for scientists and for the scientific knowledge more generally. Should it be kept at all, the letter of recommendation should be written jointly between the mentors or advisors and the trainees to prevent any potential errors and biased language and to serve as a good mentoring opportunity promoting self-reflection [10]. Even though, this 
would not remove its deficiencies mentioned above, so it should be better to remove such educational accessories from academia to reduce their pull string effects and to keep academia as an objective field as possible.

\section{Disclosure: None.}

\section{References}

1. Nicklin, J.M. and S.G. Roch, Letters of Recommendation: Controversy and consensus from expert perspectives. International Journal of Selection and Assessment, 2009. 17(1): p. 76-91.

2. Saudek, K., et al., Dear Program Director: Deciphering Letters of Recommendation. J Grad Med Educ, 2018. 10(3): p. 261-266.

3. Dirschl, D.R. and G.L. Adams, Reliability in evaluating letters of recommendation. Academic Medicine, 2000. 75(10): p. 1029.

4. DeZee, K.J., et al., Letters of recommendation: rating, writing, and reading by clerkship directors of internal medicine. Teach Learn Med, 2009. 21(2): p. 153-8.

5. Nehler, M., Letters of Recommendation: How Do They Fit Into the Modern Application? J Grad Med Educ, 2018. 10(3): p. 267-268.

6. Moustafa, K., Does the Cover Letter Really Matter? Sci Eng Ethics, 2015. 21(4): p. 839-41.

7. Nicklin, J.M. and S.G. Roch, Biases influencing recommendation letter contents: Physical attractiveness and gender. Journal of Applied Social Psychology, 2008. 38(12): p. 3053-3074.

8. Aamodt, M.G., Symposium presented at the 20th annual conference of the Society for Industrial and Organizational Psychology, Los Angeles, CA. 2005.

9. Maruca-Sullivan, P.E., et al., Plagiarised letters of recommendation submitted for the National Resident Matching Program. Med Educ, 2018. 52(6): p. 632-640.

10. Master, Z., A Mentoring Opportunity: A Joint Effort in Writing Letters of Recommendation. Account Res, 2017. 24(1): p. 52-59. 